\title{
Effects of Climbing Fiber Driven Inhibition on Purkinje Neuron Spiking
}

\author{
Paul J. Mathews, Ka Hung Lee, Zechun Peng, Carolyn R. Houser, and Thomas S. Otis \\ Department of Neurobiology, Brain Research Institute, and Integrative Center for Learning and Memory, David Geffen School of Medicine at University of \\ California, Los Angeles, Los Angeles, California 90095
}

\begin{abstract}
Climbing fiber (CF) input to the cerebellum is thought to instruct associative motor memory formation through its effects on multiple sites within the cerebellar circuit. We used adeno-associated viral delivery of channelrhodopsin-2 (ChR2) to inferior olivary neurons to selectively express $\mathrm{ChR} 2 \mathrm{in} \mathrm{CFs}$, achieving nearly complete transfection of CFs in the caudal cerebellar lobules of rats. As expected, optical stimulation of ChR2-expressing CFs generates complex spike responses in individual Purkinje neurons (PNs); in addition we found that such stimulation recruits a network of inhibitory interneurons in the molecular layer. This CF-driven disynaptic inhibition prolongs the postcomplex spike pause observed when spontaneously firing PNs receive direct CF input; such inhibition also elicits pauses in spontaneously firing PNs not receiving direct CF input. Baseline firing rates of PNs are strongly suppressed by low-frequency $(2 \mathrm{~Hz})$ stimulation of CFs, and this suppression is partly relieved by blocking synaptic inhibition. We conclude that CF-driven, disynaptic inhibition has a major influence on PN excitability and contributes to the widely observed negative correlation between complex and simple spike rates. Because they receive input from many $\mathrm{CFs}$, molecular layer interneurons are well positioned to detect the spatiotemporal patterns of CF activity believed to encode error signals. Together, our findings suggest that such inhibition may bind together groups of Purkinje neurons to provide instructive signals to downstream sites in the cerebellar circuit.
\end{abstract}

\section{Introduction}

The climbing fiber (CF) pathway from the inferior olive (IO) to the cerebellum plays a pivotal role in cerebellar forms of motor learning. In addition to being required for the induction of motor learning (Marr, 1969; Albus, 1971; Ito, 1972; Mauk et al., 1986; Welsh and Harvey, 1998), CFs are hypothesized to convey error or teaching signals that trigger forms of heterosynaptic plasticity at multiple sites within the cerebellar circuit (Simpson and Alley, 1974; Gilbert and Thach, 1977; Medina et al., 2002; Medina and Lisberger, 2008). In the cerebellar cortex, activation of the single CF innervating each Purkinje neuron (PN) generates a complex spike, one of the most robust synaptic responses in the brain (Eccles et al., 1964). This burst response is typically followed by a transient pause in intrinsic, spontaneous PN activity (Granit and Phillips, 1956; Bell and Grimm, 1969; Bloedel and Roberts, 1971).

Even though CFs form strong excitatory PN synapses, they exert a net suppressive influence on their excitability. Stimulation of the IO decreases the high baseline $\mathrm{PN}$ spiking rate while IO

Received Aug. 16, 2012; revised 0ct. 4, 2012; accepted 0ct. 31, 2012.

Author contributions: C.R.H. and T.S.O. designed research; P.J.M., K.H.L., and Z.P. performed research; P.J.M., K.H.L., Z.P., and T.S.O. analyzed data; P.J.M. and T.S.O. wrote the paper.

This work was supported by the National Institutes of Health R01 NS079363 and R01 NS068408 (T.S.0.), S10 RR0290267 (T.S.O.), and R01 NS075245 (C.R.H.); National Research Service Award NS074719 (P.J.M.); and by the McKnight Foundation (T.S.O.). We are grateful to Drs. Shlomo Dellal, Eve Schneider, Joyce Wondolowski, and Nace Golding for comments on this manuscript and to Dr. Arnold Scheibel for stimulating discussions. We also thank Alex Nunnelly for technical support.

The authors declare no competing financial interests.

Correspondence should be addressed to Thomas S. Otis, Neurobiology Department, 63-251, CHS, 650 Charles Young Drive, University of California Los Angeles, Los Angeles, CA 90095-8347. E-mail: otist@ucla.edu.

DOI:10.1523/JNEUROSCI.3916-12.2012

Copyright $\odot 2012$ the authors $\quad 0270-6474 / 12 / 3217988-10 \$ 15.00 / 0$ inactivation results in increased spiking (Colin et al., 1980; Montarolo et al., 1982; Demer et al., 1985; Savio and Tempia, 1985; Cerminara and Rawson, 2004). Sensory-evoked activity reflects this relationship as PNs and CFs fire antiphasically in response to vestibular stimuli (Barmack and Shojaku, 1995), an effect that is abolished by IO lesions (Barmack and Yakhnitsa, 2011). These effects demonstrate that CF input strongly modulates spike output from PNs on both the millisecond and steady-state timescales. However, there remain questions as to the mechanism by which CFs inhibit PNs. It has been suggested that $\mathrm{Ca}^{2+}$-activated potassium channels and cerebellar inhibitory interneurons play a strong role in shaping both the postcomplex spike pause and spontaneous PN firing rate (Llinás and Sugimori, 1980a, b; Savio and Tempia, 1985). Until recently, evidence for the direct recruitment of inhibitory networks in the cerebellar cortex by CFs has been indirect.

Here we address these issues by targeting expression of channelrhodopsin-2 (ChR2) to IO neurons within the rat brainstem allowing us to selectively stimulate groups of CFs synchronously in an acute brain slice. In addition to eliciting PN complex spikes, we find that CF activation drives activity in cerebellar molecular layer interneurons (MLIs) as suggested by recent work (Jörntell and Ekerot, 2003; Szapiro and Barbour, 2007). In agreement with these previous findings our recordings show that each interneuron is activated by spillover of glutamate from multiple CFs, a mechanism sensitive to the spatiotemporal pattern of CF activity. CF-driven inhibition causes PNs that do not experience a direct CF input to pause, and it leads to a prolongation of the complex spike pause in PNs with an active CF. Experiments detailed here further the idea that CF-driven inhibition of PNs is 

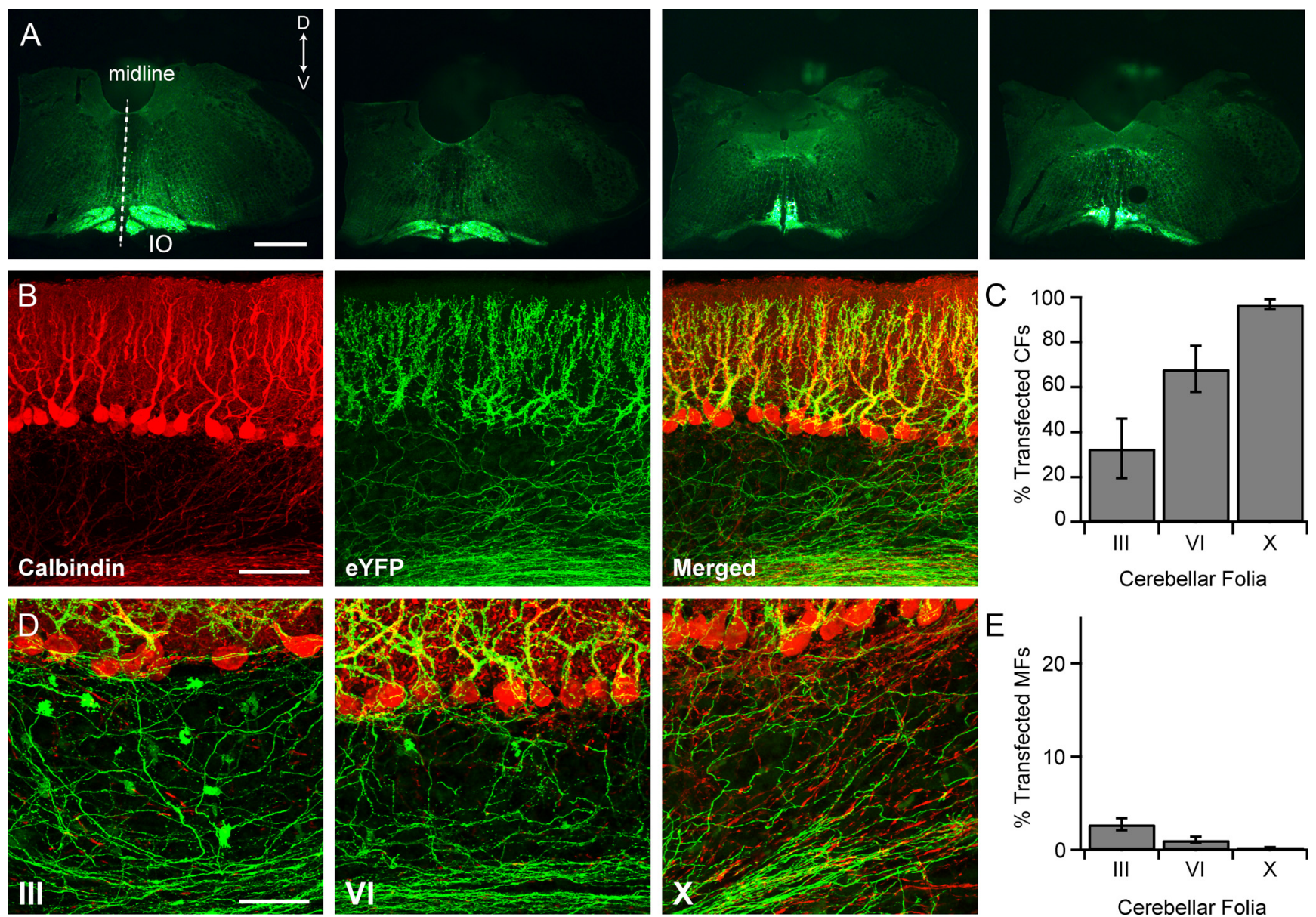

Figure 1. AAV injections in the 10 lead to widespread expression of ChR2 fused with an enhanced yellow fluorescent protein (ChR2-eYFP) in the 10 and throughout most of the cerebellar cortex. $A$, Four confocal images of transverse brainstem slices obtained from a rat injected in the I0 with AAV 2/5 $\alpha$ CaMKII-ChR2-eYFP. Each slice is $\sim 600 \mu$ m more caudal than the one to the left. Dorsal, D; ventral, V. Scale bar, $1 \mathrm{~mm}$. B, Confocal images of PNs (red, calbindin immunocytochemistry) and (Fs (green, ChR2-eYFP) in folia X of the cerebellar cortex. Scale bar, $100 \mu \mathrm{m}$. C, Plot of the percentage of (CFs transfected with ChR2-eYFP in different folia. $n=4$. D. Confocal images of PNs (red, calbindin immunocytochemistry), CFs (green, native eYFP), and a small number of MFs in lobules III, VI, and X of the cerebellar cortex. Mistargeting of ChR2 in MF terminals (readily identifiable by their rosette morphology) are observed most frequently in anterior lobes where transfected CF expression is the lowest. Scale bar, $50 \mu \mathrm{m}$. $E$, Bar graph indicating the small percentage of MF rosettes mistargeted using the AAV- $\alpha$ CaMKII-ChR2-eYFP method in different folia.

important for transforming modular CF input into an instructive signal in the deep cerebellar nucleus, in this way providing a concerted teaching signal to distributed sites within the cerebellar circuit.

\section{Materials and Methods}

Viral injection. Sprague Dawley rats of either sex were housed with a $12 \mathrm{~h}$ light/dark cycle and given ad libitum food and water. They were handled in accordance with the University of California Los Angeles Institutional Animal Care and Use Committee. Stereotactic surgeries were conducted on 1- to 2-month-old rats under ketamine/xylazine anesthesia. Glass pipettes mounted on a Nanoject microinjection unit (Drummond Scientific) were used to inject $0.2-0.4 \mu \mathrm{l}$ of AAV2/5CaMKII $\alpha$-hChR2(H134R)-eYFP solution (University of North Carolina Vector Core) per site.

Acute brain slice preparation. Parasagittal cerebellar slices $(300 \mu \mathrm{m})$ were prepared by removing the brain $4-8$ weeks post viral infection, immersing it in an ice-cold $\left(4^{\circ} \mathrm{C}\right)$, low-sodium cutting solution and sectioning it using a vibratome (Leica VT-1000). Slices were then incubated for $\sim 30 \mathrm{~min}$. at $35^{\circ} \mathrm{C}$ and allowed to sit at room temperature before electrophysiological recordings. Both the cutting and recording media were bubbled with $95 \% \mathrm{O}_{2}$ and $5 \% \mathrm{CO}_{2}$. The low-sodium cutting solution consisted of the following (in $\mathrm{mM}$ ): $82.7 \mathrm{NaCl}, 2.4 \mathrm{KCl}, 1.4$ $\mathrm{NaH}_{2} \mathrm{PO}_{4}, 0.5 \mathrm{CaCl}_{2}, 6.8 \mathrm{MgCl}_{2}, 23.8 \mathrm{NaHCO}_{3}, 65$ sucrose, and 23.7 dextrose, and the recording solution consisted of the following (in $\mathrm{mM}$ ):
$119 \mathrm{NaCl}, 2.5 \mathrm{KCl}, 1.25 \mathrm{NaH}_{2} \mathrm{PO}_{4}, 2 \mathrm{CaCl}_{2}, 1 \mathrm{MgCl}_{2}, 26 \mathrm{NaHCO}_{3}$, and 25 dextrose.

Electrophysiology. Cells were visualized on an upright microscope (Zeiss Axioskop II or Axio Examiner) with a $40 \times$ (Axioskop) or $20 \times$ (Examiner, see Fig. 6D) water-immersion lens using either infrared differential interference contrast microscopy (Axioskop) or Dodt illumination (Examiner). All recordings were performed at near physiological temperature $\left(34 \pm 1^{\circ} \mathrm{C}\right.$ ), and acquired using pClamp9 (Molecular Devices) at $20 \mathrm{kHz}$ for intracellular recordings and $5-10 \mathrm{kHz}$ for extracellular recordings. A Multiclamp 700B or Axopatch 1D amplifier (Molecular Devices) was used to record electrophysiological signals. In voltage-clamp, the pipette and cellular capacitance $(\leq 80 \%)$ were compensated for using onboard circuitry. To improve the voltage-clamp and limit escaped spikes in PNs when recording CF synaptic currents, the voltage-gated $\mathrm{Na}^{+}$channel blocker QX314 was included in the recording pipette and neurons were additionally clamped to $\sim 0 \mathrm{mV}$, near the excitatory reversal potential. The pipette solution for $\mathrm{PN}$ voltage-clamp recordings contained the following (in $\mathrm{mM}$ ): $127 \mathrm{CsMSO}_{3}, 10 \mathrm{CsCl}, 10$ HEPES, $0.16 \mathrm{CaCl}_{2}, 2 \mathrm{MgCl}_{2}, 0.2$ EGTA, $14 \mathrm{Na}_{2}$-phosphocreatine, 2 MgATP, 0.4 NaGTP, and 4 QX314-Cl. For all intracellular MLI recordings the pipette solutions consisted of the following (in $\mathrm{mM}$ ): 126 $\mathrm{KMethSO}_{3}, 14 \mathrm{KCl}, 10$ HEPES, $0.16 \mathrm{CaCl}_{2}, 5 \mathrm{EGTA}, 5 \mathrm{Na}_{2}$ phosphocreatine, 4 MgATP, $0.4 \mathrm{NaGTP}$, and 2 QX314-Cl. All extracellular recording pipettes were filled with external recording solution. Recording pipettes were 3.5-5 M $\Omega$ for MLIs and 2.5-4 $\mathrm{M} \Omega$ for PNs. 

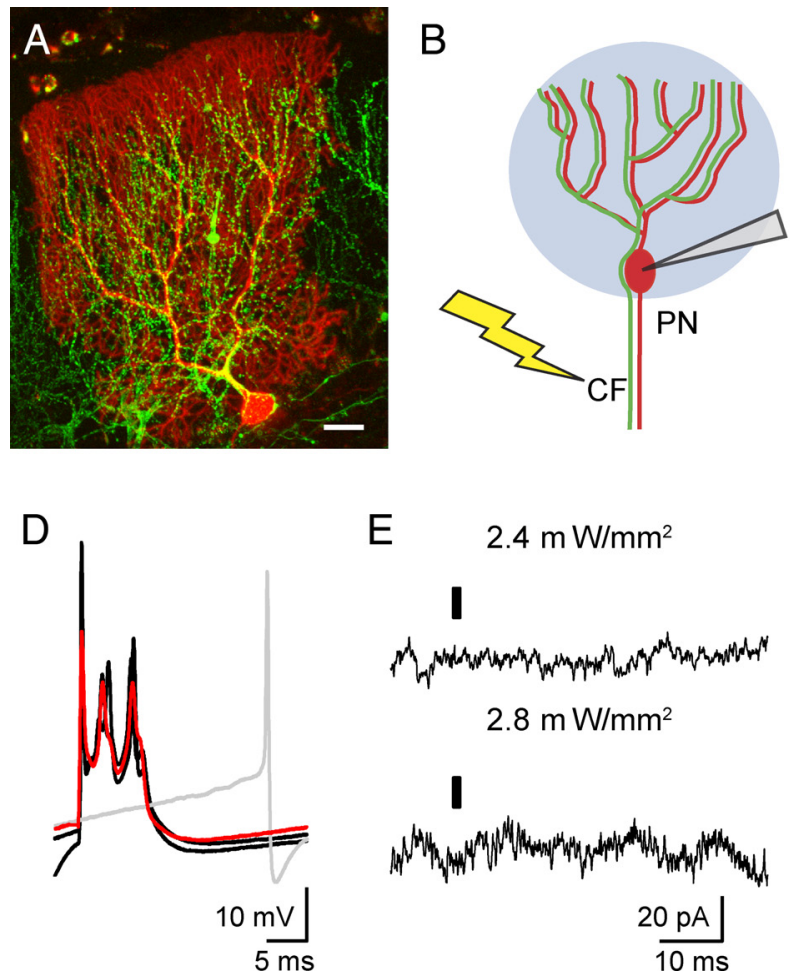

$\mathrm{E}$
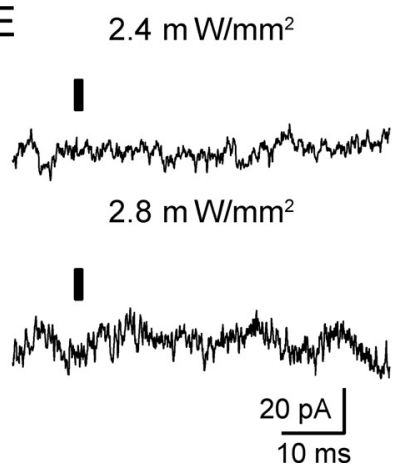

C

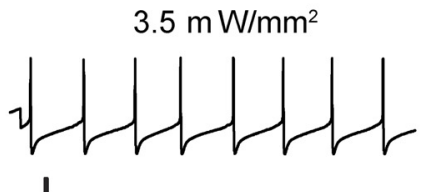

$5.3 \mathrm{~mW} / \mathrm{mm}^{2}$

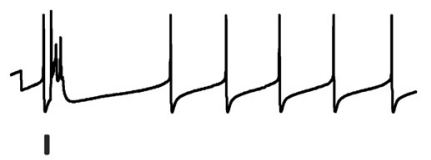

$2.6 \mathrm{~m} \mathrm{~W} / \mathrm{mm}^{2}$

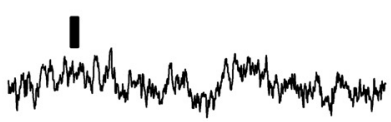

$3 \mathrm{~m} \mathrm{~W} / \mathrm{mm}^{2}$

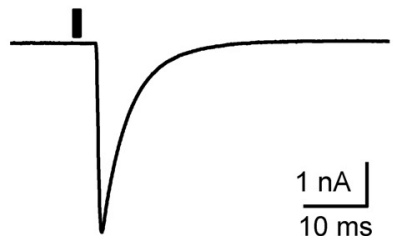

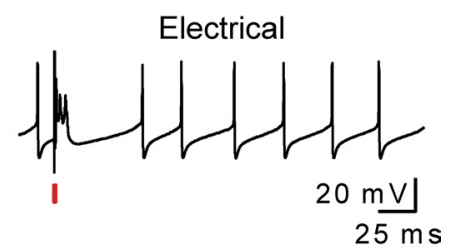

$4.38 \mathrm{~m} \mathrm{~W} / \mathrm{mm}^{2}$

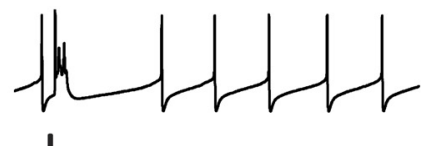

Electrica

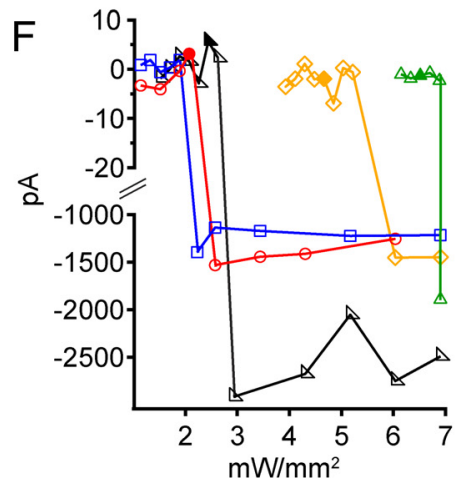

Figure 2. Optical activation of ChR2-eYFP-expressing CFs results in all-or-none PN responses. A, Multiphoton image of ChR2-eYFP-expressing CFs (green) and a PN filled with Alexa 594 during a whole-cell recording (red) in a parasagittal cerebellar slice. Scale bar, $50 \mu \mathrm{m}$. B, Diagram illustrating the two methods used to stimulate the same CF input to an individual PN. Blue circle indicates $0.6-1 \mathrm{~ms}$ pulses of blue light $(470 \mathrm{~nm}$ ) used to activate ChR2 expressed in CF. Lightning bolt indicates $0.1 \mathrm{~ms}$ electrical stimuli used to electrically activate CF in granule cell layer close to the recorded PN. C, Complex spike responses recorded from a current-clamped PN in response to optical (black line) or electrical (red line) stimuli. Illumination intensity is indicated above traces. D, Overlaid voltage responses from Cillustrate the similar complex spike waveforms elicited by optical (black) and electrical (red) stimuli. The gray trace illustrates subthreshold optical stimulation. The electrical stimulus artifact has been removed for clarity. $E$, PN voltage-clamp traces shown here are the result of light activation that was either subthreshold $\left(2.4,2.6\right.$, and $\left.2.8 \mathrm{~mW} / \mathrm{mm}^{2}\right)$ or suprathreshold $\left(3 \mathrm{~mW} / \mathrm{mm}^{2}\right)$, giving rise to large (nA) CF-like EPSC. Response to $3 \mathrm{~mW} / \mathrm{mm}^{2}$ stimulus was recorded at $V_{\mathrm{m}}=0 \mathrm{mV}$, all others were recorded at $-70 \mathrm{mV}$ (see Materials and Methods). Responses are averages of $4-10$ trials. $\boldsymbol{F}$, Plot showing that light stimulation leads to all-or-none $C F$ activation in PNs. Currents, like in $\boldsymbol{E}$, were recorded at $-70 \mathrm{mV}$ for subthreshold responses (plotted for the intensity range from 10 to $20 \mathrm{pA}$ ) and $0 \mathrm{mV}$ for large (F responses (plotted for the range -1000 to $-3000 \mathrm{pA}$ ). Solid symbols indicate intensities at which there were both failures and successes in the recorded PN; however, only the failure amplitudes have been averaged and plotted.

Those experiments where the recording's series resistance exceeded 15 $\mathrm{M} \Omega$ were eliminated. Data were filtered at $4 \mathrm{kHz}$. Where indicated the recording solution contained $100 \mu \mathrm{M}$ picrotoxin to block $\mathrm{GABA}_{\mathrm{A}^{-}}$ mediated currents. For MLI recordings cells were selected from the inner one-third of the molecular layer. A small subset of recorded neurons were morphologically identified after visualizing them using $10 \mu \mathrm{M}$ Alexa 594 in the pipette. Both putative basket and stellate cells were observed indicating MLI recordings were from a mixture of MLI cell types. All reagents are from Sigma/RBI except for QX314-Cl, which was purchased from Tocris Bioscience.

Experiments were analyzed using both Clampfit and custom macros written for IgorPro (Taro Tools; Dr. Taro Ishikawa, https://sites.google. $\mathrm{com} /$ site/tarotoolsregister/). In a few experiments the spontaneous firing frequency of MLIs was too low to adequately analyze the average baseline intervals and/or poststimulus pauses, these cells were excluded from further analysis. However, these cells were included in counts describing response profiles. The change in spike output for both PNs and MLIs as a result of CF stimulation was determined by computing and integrating the peristimulus time histogram (PSTH) (Fetz and Gustafsson, 1983). The linear fit of the prestimulus baseline ( $\geq 80 \mathrm{~ms}$ ) was extrapolated and subtracted from the entire integrated PSTH. Changes in spike output could then be measured at the peak (spike gain) or trough (spike loss) of the resulting subtracted cumulative histogram (cumPSTH). All statistics were computed using a two-tailed Student's $t$ test (paired in cases of within-experiment manipulation). Error bars and shaded error regions in figures represent \pm SEM.

Optical stimulation. Optical stimulation of slices was achieved using an LED light source (470 nм; THORlabs; hereafter referred to as "blue light") projected through the epifluorescence pathway of the micro- scope. Since ChR2-eYFP-expressing mossy fibers (MF) were easily identified under epifluorescence at the beginning of each slice experiment, these recordings were performed only in lobules lacking eYFP-positive MFs (see Fig. 1 and associated text for more details). In addition, optical stimuli used for ChR2 activation were restricted to the PN and molecular layers of the cerebellar cortex using an iris in the epifluorescence pathway to prevent further MF activation. The illumination intensities used for CF activation depended on the experimental protocol and density of ChR2 expression (range: $1-7 \mathrm{~mW} / \mathrm{mm}^{2}$ as measured out of the objective). In most cases $1-2 \mathrm{~mW} / \mathrm{mm}^{2}$ was sufficient to elicit optical CF activation.

To visualize the infected cells a custom-designed YFP cube (Exc. 504/12 nm, Em. 542/27 nm, Dichroic 520 nm; Semrock) was used to limit the amount of stimulatory blue light, otherwise a cube designed for GFP (Exc. 470/40, Em. 525/50, Dichroic 495) was used for optical stimulation. Pulses of light were either triggered directly by TTL signals from pClamp to the LED controller or through a signal generator (Master 8; AMPI) triggered by pClamp. For peristimulus plots in Figures 5-7, optical stimulation was elicited at $t=0 \mathrm{~ms}$.

For experiments where adjacent CFs were activated during PN recordings (Fig. 7), the optical intensity was set by illuminating the recorded PN and increasing the optical intensity until a complex spike was observed. The illumination region was then moved laterally by repositioning the microscope on its translation table relative to the sample. In this way the illuminated region can be effectively moved along the folium such that the complex spike to the recorded PN was no longer observed while still allowing CF-driven activation of adjacent MLIs.

Imaging and density analysis. Multiphoton images were taken from $300-\mu \mathrm{m}$-thick, ACSF-perfused acute slices after patching and filling the 
A

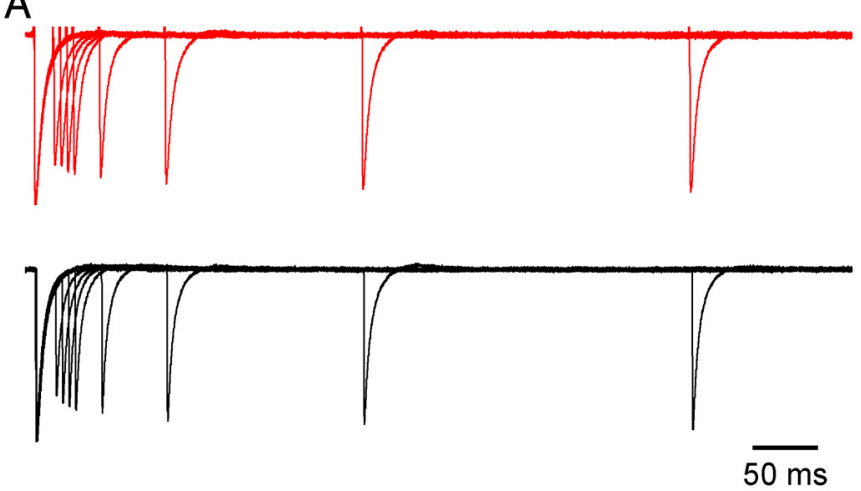

B 1.0

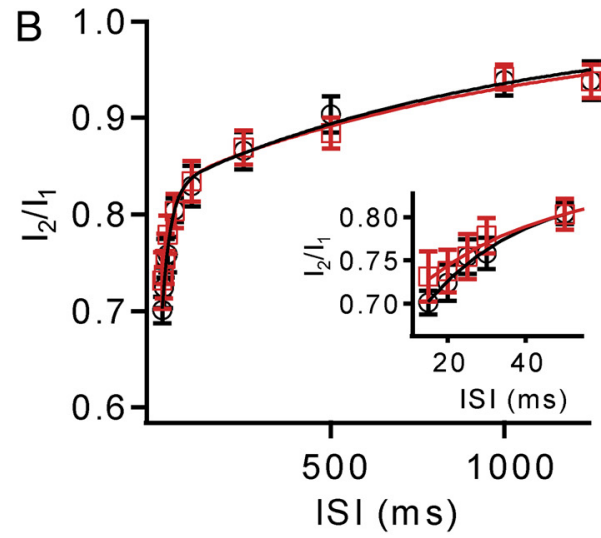

C

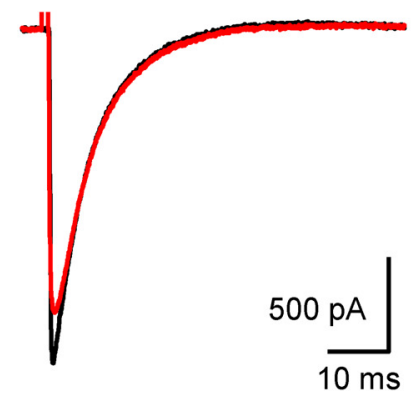

Amplitude

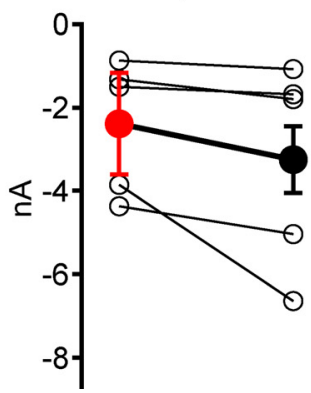

$\tau$ decay

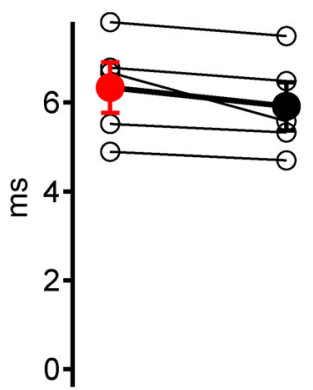

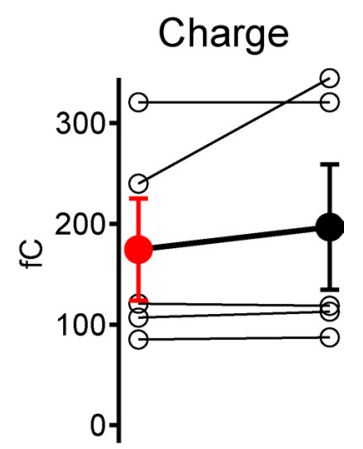

Figure 3. Optical activation of ChR2-eYFP-expressing CFs faithfully reproduces physiological activation. A, CF synaptic currents resulting from pairs of optical (black) or electrical (red) stimuli with differing interstimulus intervals (ISI; 5-1250 ms) are displayed. Currents normalized to first pulse. B, Both electrical (red squares) and optical (black circles) stimulation result in similar, stereotypical paired-pulse depression of CF currents. Curves are two exponential fits to average data. Inset, Increased time resolution for shorter ISIs. C, Within the same PNs, CF EPSCs are not significantly different for the two stimulus paradigms (amplitude: Electrical $-2.4 \pm 0.8 \mathrm{nA}, 0$ ptical $-3.3 \pm 1.2 \mathrm{nA}, p=0.1 ; \tau$-decay: Electrical $6.3 \pm 0.6 \mathrm{~ms}, 0$ ptical $5.9 \pm 0.5 \mathrm{~ms}, p=0.6$; charge: Electrical $175 \pm$ $51 \mathrm{fC}$, Optical $197 \pm 62 \mathrm{fC}, p=0.8 ; n=5)$.

identified PN with Alexa 594 (Invitrogen). The pipette was pulled off before imaging on a multiphoton microscope (3i VIVO).

To quantify the expression levels of ChR2 as the result of viral infection alternate tissue slices (three slices each from four animals) were placed into paraformaldehyde (4\%) for subsequent neuroanatomical analysis during slicing for physiology experiments. These slices were re-sectioned on a cryostat at $30 \mu \mathrm{m}$ thicknesses and processed with standard immunofluorescence methods, using a mouse monoclonal antibody to calbindin D-28K (Clone CB-955, 1:5,000; Sigma) as the primary antibody for labeling PNs, with goat anti-mouse IgG conjugated to Alexa Fluor 555 (Invitrogen) as the secondary antibody. The immunolabeled PNs and ChR2-eYFP-expressing structures were imaged with a confocal microscope (LSM 510 META; Zeiss). Three digital images of $z$-stacks at $1 \mu \mathrm{m}$ intervals were obtained from each studied folium (III, VI, or X) with a $40 \times$ objective. Excitation spectra of 488 and 543 were used to visualize the eYFP-expressing fibers and immunolabeled PNs, respectively. $Z$-stacks of the double-labeled images were projected, and the extent of ChR2-eYFP labeling was determined (total of 36 projections). All PNs with and without an associated eYFP-labeled CF were counted throughout each image stack. The ratio of ChR2-expressing versus nonexpressing CFs was calculated based on the fact that PNs receive only a single CF input. Therefore, the ratio of PNs associated versus those not associated with a ChR2-eYFP-positive CF was used as a proxy for determining the overall expression levels of ChR2-eYFP in CFs. A PN was considered positively associated with a transfected $\mathrm{CF}$ if the fluorescently labeled CF faithfully followed the trajectory of the proximal PN dendrite in the confocal image stack. This procedure was repeated in three slices for folia III, VI, and X in each of four animals. The percentage of mistargeted MFs was determined by counting morphologically identifiable MF terminals or rosettes throughout the full extent of the granule cell layer directly below the PN regions in which CF labeling was analyzed as detailed above. The density of eYFP-labeled MF terminals or rosettes within these regions was then calculated based on the volume of the granule cell layer examined. The mistargeted MF density was divided by an estimate of the total density of cerebellar MF rosettes to get the overall percentage of mistargeting. The total MF density estimate was based on values found in the literature indicating that there are $\sim 98,800 \mathrm{MFs} / \mathrm{mm}^{3}$ (Palkovits et al., 1972).

\section{Results}

\section{Viral methods allow ChR2 to be specifically expressed in} cerebellar CFs

Optogenetic approaches have been successfully used to activate specific neuronal projections in a number of different brain regions including the striatum, cortex, and cerebellum (Mattis et al., 2012). To examine the effect of synchronous CF activity on particular circuit elements in the cerebellar cortex, we made stereotactic injections of adeno-associated virus (AAV) encoding ChR2 fused to eYFP, and under the control of an $\alpha$ CaMKII promoter into the IO of adult rats (see Material and Methods). The $\alpha$ CaMKII promoter was chosen for its relatively restricted expression in IO neurons within the brainstem (Ochiishi et al., 1998). Following a 4-8 week period to allow for adequate expression, fluorescence microscopy was used to document the presence of ChR2-eYFP in IO neurons and their axonal endings (Fig. 1). Viral transfection led to robust, but restricted expression of ChR2-eYFP in neurons throughout most of the IO. In addition, ChR2-eYFP was highly expressed in IO axons including CF axonal arbors terminating millimeters away in the cerebellar cortex.

In mature animals each $\mathrm{PN}$ receives input from a single $\mathrm{CF}$, and this simple anatomical rule as well as the large size of the $\mathrm{CF}$ endings allowed us to quantify transfection efficiency. To do this we examined areas of high expression in different lobules of cer- 
A

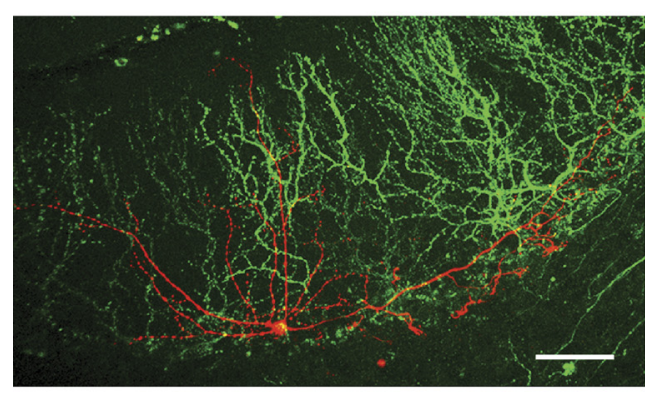

B

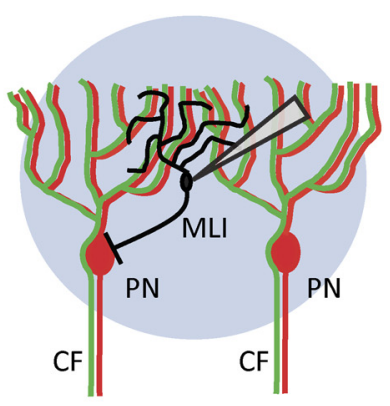

D Parallel fiber

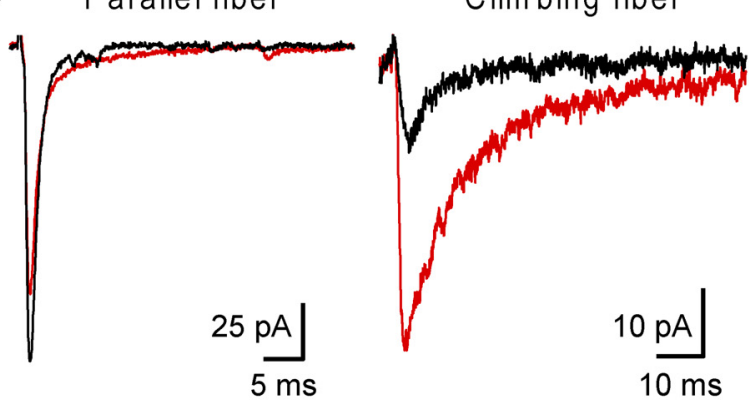

F
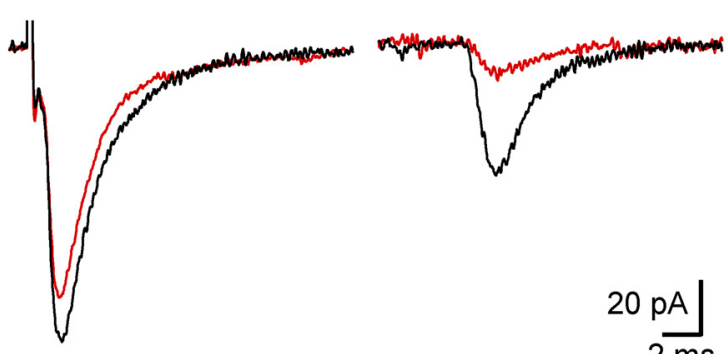

E

G
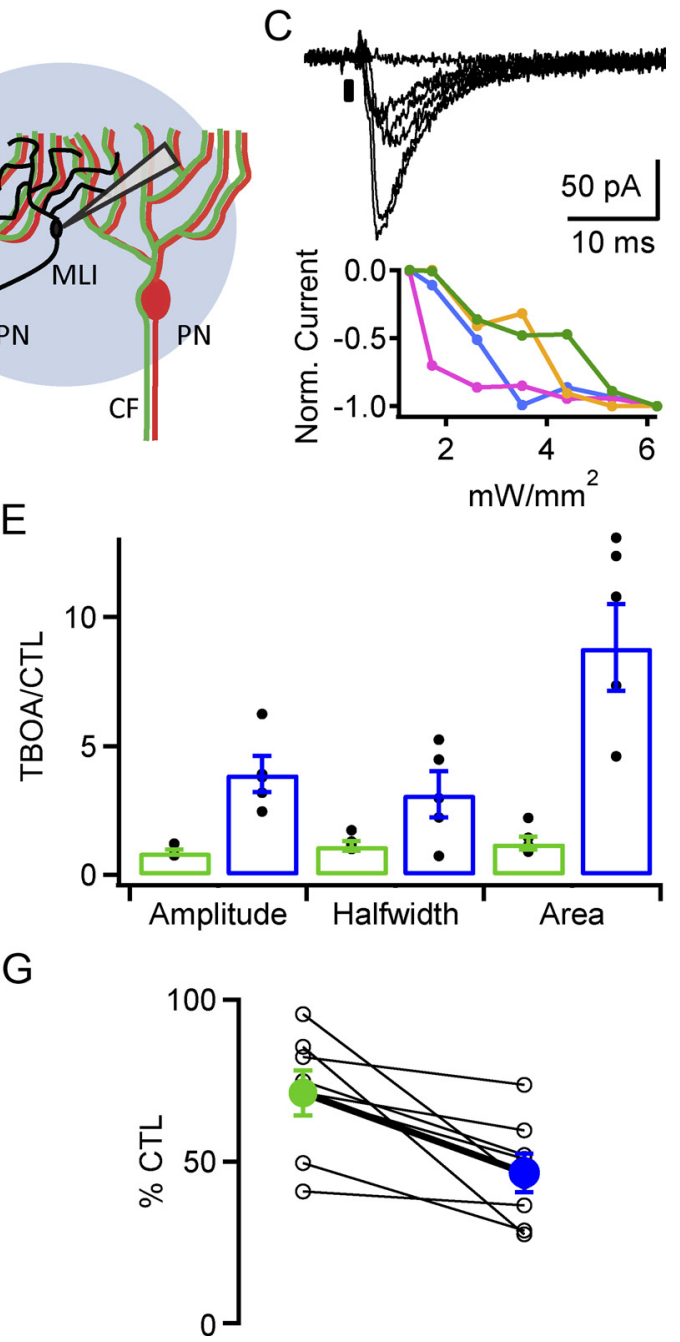

Figure 4. CF-elicited currents are mediated by glutamate spillover in MLIs. A, Multiphoton image of an Alexa 594-filled MLI (red) in a slice containing ChR2-eYFP-expressing CFs (green). Scale bar, $50 \mu \mathrm{m} . \boldsymbol{B}$, Schematic illustrating intracellular MLI recordings in response to optical stimulation of multiple CFs. C, In response to increasing intensities of optical CF stimulation MLI currents increase in a stepwise function (optical intensities: $1.3-6.2 \mathrm{~mW} / \mathrm{mm}^{2}$; top). In different cells the threshold intensity for CFs differs, and is likely a function of differences in ChR2 expression levels and depth of CF within slice (bottom). Green plot corresponds to black traces above. Timing of optical stimulus $(0.6 \mathrm{~ms})$ is indicated by black box. D, Example MLI currents elicited by either electrical stimulation of PF (0.1 ms) synaptic inputs (left), or optical CF stimulation in the same MLI (right, $0.6 \mathrm{~ms}$ ) before (black) and after (red) TBOA application. $E$, Summary graph of the ratio of change in control and TBOA for the PF (green) and CF (blue) current attributes amplitude, half-width, and area. $F$, Similar to $D, M L I$ current responses to electrical PF or optical CF stimulation in the same cell are illustrated. The effects of bath application of DGG were compared for each stimulation pathway. G, Plot of percentage control amplitude for PF (green) and CF (blue) stimulation as a result of DGG application.

ebellar cortex and determined the fraction of PNs associated with ChR2-eYFP-positive CFs (see Materials and Methods). Such analyses performed on tissue obtained from four animals showed that expression was nearly complete in selected areas of the posterior cerebellum (lobule VI, $68 \pm 10 \%$; lobule X, $97 \pm 2 \%$ ), but was lower in anterior regions (lobule III, $33 \pm 13 \%$ Fig. $1 C$ ). To assess the degree of mistargeting to circuit elements other than CFs, we counted ChR2-eYFP-positive MF boutons in the same confocal micrographs used for measurements described above. In each of the folia examined, $<2.7 \%$ on average of MF endings were ChR2-eYFP positive (range $0-5.6 \%$ for individual folia; Fig. $1 D, E)$. Thus, comparisons of CF and MF labeling indicate highly efficient and specific expression in CFs throughout the cerebellum.

Brief optical pulses produce physiologically similar CF responses in PNs

To confirm functional expression of ChR2 in CFs we performed whole-cell recordings from PNs in posterior lobes (VI-X) of cer- ebellar slices prepared from virally injected animals (Fig. 2A,B). Current-clamp recordings from PNs showed that brief (0.5-1 $\mathrm{ms}$ ), blue light pulses elicited all-or-none complex spikes superimposed on spontaneous tonic firing, often referred to as simple spikes (9 of 9 cells; Fig. 2C). As expected for complex spikes (Linden and Connor, 1995), optically stimulated responses are highly stereotypical and closely resemble the classically reported waveform; in addition they were very similar to the electrically evoked waveform in the same cell (Fig. $2 D$ ). In voltage-clamp, responses were also confirmed to be all or none, and careful scrutiny of "failure" traces showed no evidence of small, graded light-evoked currents that might arise from MF expression (Fig. $2 E, F)$. In addition, we compared properties of electrically and optically evoked currents under voltage-clamp conditions in the same cells and found that the kinetic properties of individual EPSCs and short-term synaptic plasticity of these currents were very similar (recovery time constants: $\tau$-fast Electric: $28 \pm 6 \mathrm{~ms}$, Optical: $21 \pm 2 \mathrm{~ms}, p=0.34$; $\tau$-slow Electric: $1021 \pm 104 \mathrm{~ms}$, Optical $871 \pm 190, p=0.30 n=5$; Fig. $3 A-C$ ). These results 

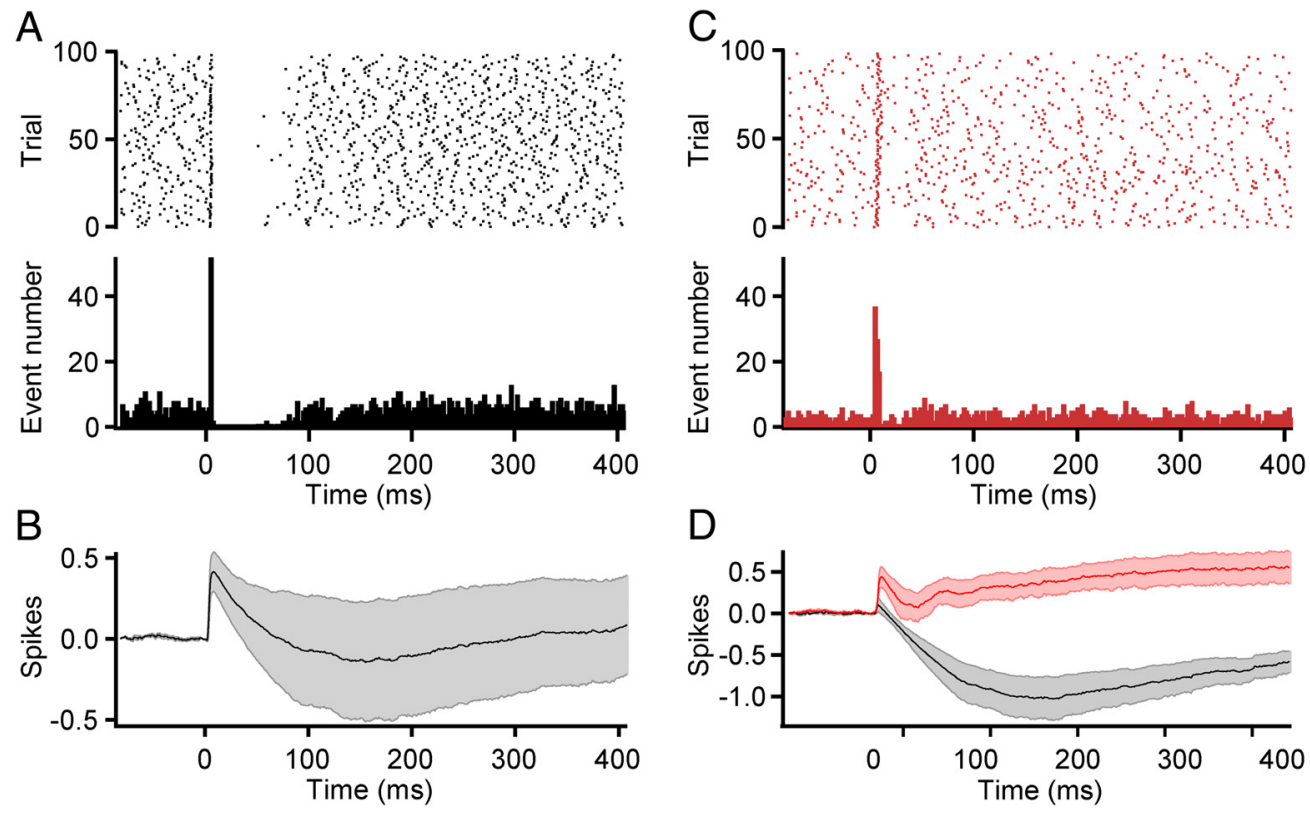

Figure 5. CF excitation of MLIs results in action potential generation and lateral MLI-to-MLI inhibition. $A$, Raster plot (top) and corresponding PSTH (bottom) of the spontaneous and synchronized spikes from an extracellularly recorded MLI during 100 successive optical CF stimuli delivered at $0.14 \mathrm{~Hz}$. Intensity, up to $7 \mathrm{~mW} / \mathrm{mm}^{2} ;$ Bin, $2 \mathrm{~ms}$. B, Average cumPSTH of $20 \mathrm{MLI}$ neurons that regularly responded with an action potential to CFoptical stimulation. Action potentials were triggered by $43 \pm 10 \%$ of the stimuli with a mean delay of $5.21 \pm 0.3 \mathrm{~ms}(n=20)$. In 12 of 20 cells the excitatory phase was followed by a pause (141.6 $\pm 27.3 \mathrm{~ms}$ corresponding to $3.0 \pm 0.6$ periods). Bin, $1 \mathrm{~ms}$. C, Raster plot (top) and PSTHs (bottom) in response to optical CF activation in the same cell as $A$, but in the presence of picrotoxin to block lateral MLI-to-MLL inhibition. D, Summary cumPSTH illustrating the effects of blocking lateral inhibition in a subset of neurons that demonstrated CF-driven pauses in MLI activity $(n=6)$. Control, black; picrotoxin, red. Bin, $1 \mathrm{~ms}$.

indicate that ChR2-elicited responses result from optically triggered spikes in CF axons leading to physiologically similar CF responses that were very comparable to those evoked by electrical stimuli.

\section{CFs cooperate to elicit MLI currents through glutamate spillover}

Prior work suggests that in addition to PNs, CFs in the molecular layer of the cerebellar cortex excite local, feedforward MLIs, and that this excitation occurs by an unconventional, spillovermediated mechanism (Jörntell and Ekerot, 2003; Szapiro and Barbour, 2007). To validate and extend these findings, blue light pulses were delivered with LED illumination levels just above threshold $\left(\sim 1-2 \mathrm{~mW} / \mathrm{mm}^{2}\right)$ in areas where ChR2-eYFP was expressed in many CFs (Fig. $4 A, B$ ). This stimulation resulted in variable amplitude currents recorded from different MLIs (range -4.3 to $-116.2 \mathrm{pA}$, mean $-38.1 \pm 26 \mathrm{pA}, n=48$ cells; Fig. $4 C$, top). Stimulation over a range of optical intensities gave rise to stepwise increases in response, strongly suggesting that multiple CFs converge onto each MLI (maximum current range -58 to -401 pA, $n=12$; Fig. $4 C$, bottom). This contrasts with currents recorded in $\mathrm{PNs}$ where only a single all-or-none response was observed over similar optical stimulation intensities (compare Figs. $4 C, 2 E, F)$. Within the same MLIs we compared electrically evoked parallel fiber (PF) synaptic responses and optically evoked CF responses. We found that the CF-mediated response was significantly more sensitive to low-affinity competitive antagonists and glutamate transport inhibitors, which indicates CF-to-MLI signaling occurs through a glutamate spillover mechanism (Fig. 4D-G). Specifically, bath application of the glutamate reuptake blocker DL-threo- $\beta$-benzyloxyaspartic acid (TBOA; $50 \mu \mathrm{M}$ ) led to large increases in the amplitude and slowing of the kinetics of CF-driven currents, but not PF-driven currents (Fig. 4D). The mean fold changes in amplitude, half- width, and area of CF currents were significantly larger than for PF currents when comparing these two inputs within the same MLI ( $p=0.04$ and $n=5$ for half-width; $p=0.002$ and $n=6$ for amplitude, $p=0.002$ and $n=6$ for area; Fig. $4 E$ ). In addition, the effects of bath application of $\gamma$-D-glutamylglycine (DGG; 375 $\mu \mathrm{M})$, a weak ionotropic glutamate receptor antagonist, were compared for each stimulation pathway. The percentage decrease in CF-elicited currents was significantly greater than those elicited by PF stimulation as a result of the DGG block of glutamate receptors $(71 \pm 7$ and $47 \pm 6 \%$ control for PF and $\mathrm{CF}$, respectively; $p=0.009$; Fig. $4 F, G)$. These findings support the proposal that CF signaling to MLIs relies on an unconventional form of signal transmission mediated by glutamate spillover (Szapiro and Barbour, 2007).

\section{Synchronous CF activation drives MLI activity}

We next examined the effects of synchronous CF excitation on MLI excitability. Minimally invasive, extracellular recordings were made to monitor MLI spiking, and brief (0.5-1 ms) optical stimuli were delivered to synchronously activate CFs (Fig. $5 A, B$ ). CF optical stimulation caused most MLIs (20/29) to spike reliably with a short latency following CF stimulation, and this excitatory phase was often followed by a pause in MLI spontaneous activity. In a minority of MLIs (9/29), CF stimulation led only to delayed inhibition, which is likely a result of MLI-to-MLI connections within a diverging network, and may reflect the fact that not all CFs are transfected. Analysis of mean cumulative PSTHs corrected for the spontaneous firing rate (cumPSTHs; see Materials and Methods) indicated that the pause arose from a combination of factors: CF triggered spikes "reset" the spontaneous cycle such that at least one full period occurred before the next spike; in addition, most pauses following the CF-induced spike were significantly longer than the interspike intervals seen during baseline firing, indicative of active MLI-mediated inhibition (237 \pm 

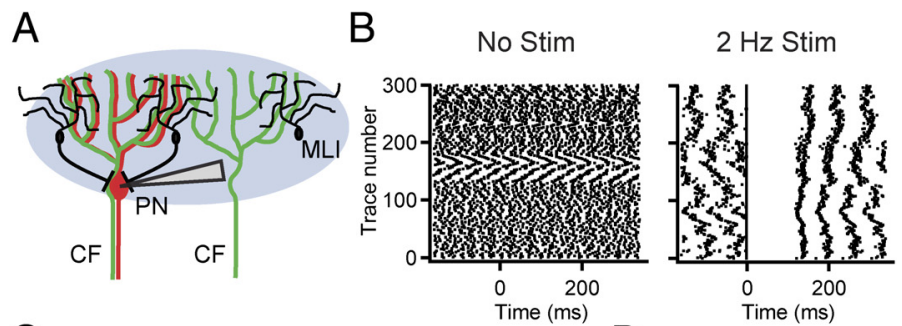

$2 \mathrm{~Hz}$ Stim + Picro
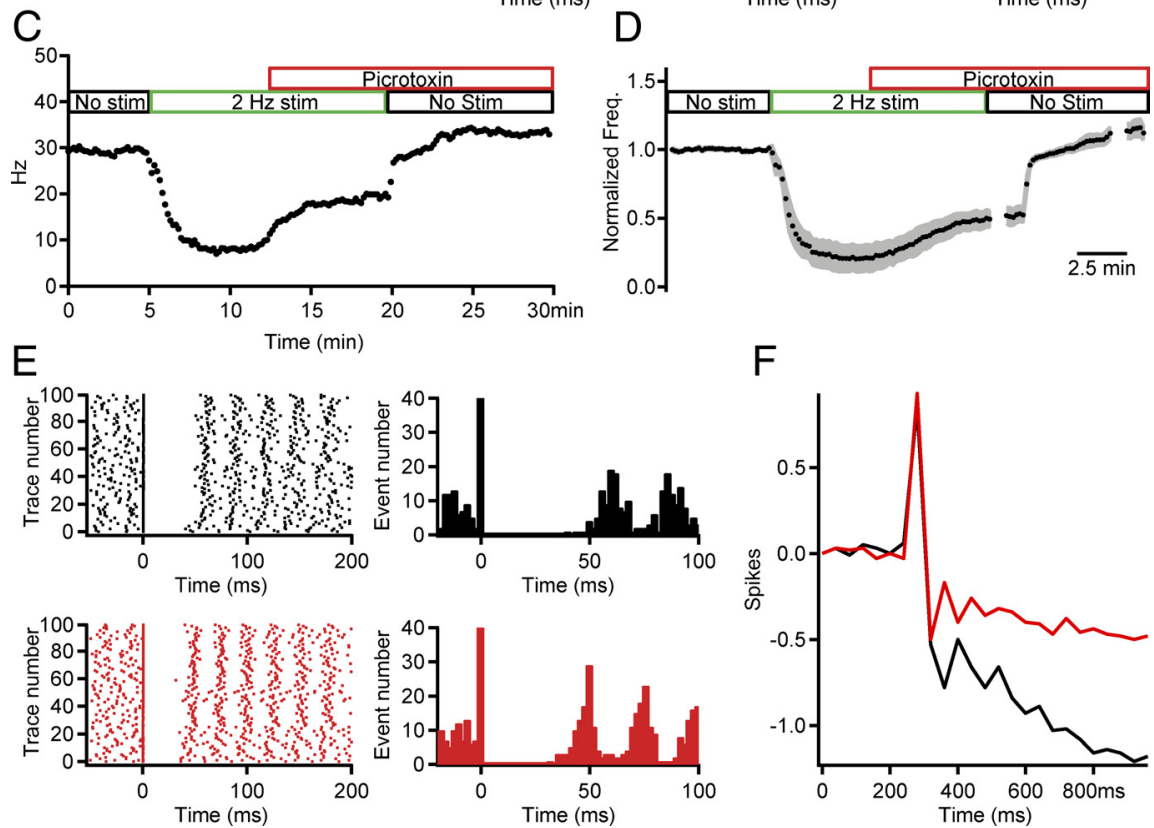

Figure 6. CF activation of feedforward inhibition is partly responsible for suppressing PN firing. $A$, Schematic of the experimental conditions using extracellular PN recordings and brief, wide-field CF optical stimulation. $\boldsymbol{B}$, Raster plots of PN activity before (left), during $2 \mathrm{~Hz}$ (F stimulation (center), and after addition of picrotoxin to block MLI-to-PN inhibition (red). C, PN firing rate versus time in an example cell. As indicated by the colored boxes above the graph, a control period with no CF stimulation (black) was followed by a period of $2 \mathrm{~Hz}$ optical CF stimulation (green). Bath perfusion of the $\mathrm{GABA}_{\mathrm{A}}$ receptor antagonist picrotoxin (red) reduced the suppressive effect of the $2 \mathrm{~Hz}$ stimulation. Upon cessation of $2 \mathrm{~Hz} \mathrm{CF}$ stimuli the firing rate returned to near control value. Each point is the average frequency over 10 s. D, Similar to $\boldsymbol{C}$, but a summary of normalized to baseline PN firing frequency for 12 cells. Bin size, $2 \mathrm{~ms}$; mean \pm shaded SEM. $\boldsymbol{E}$, Raster plot and PSTH illustrating the effects of feedforward inhibition on the postcomplex spike pause from an example cell in control (black, top) and after picrotoxin application (red, bottom). $\boldsymbol{F}$, The cumPSTH for the example cell illustrating the significantly reduced pause after picrotoxin application when compared with control. Bin size, $50 \mathrm{~ms}$. Significant effects were observed for the population of 13 PNs for which this experiment was conducted (see Results).

$36 \%$ of baseline interval, $n=7, p<0.01)$. Application of a $\mathrm{GABA}_{\mathrm{A}}$ receptor antagonist resulted in a $70 \pm 8 \%$ decrease in the first poststimulus interspike interval, a duration that is within two SDs of the mean of all interspike intervals occurring within a $100 \mathrm{~ms}$ window before the stimulus ( $38 \pm 8$ vs $49 \pm 11 \mathrm{~ms}$ for prestimulus and poststimulus intervals, respectively, $p=0.1, n=$ 6; Fig. $5 C, D)$. These data confirm MLI activation by CFs and show that this leads to a robust, delayed MLI-to-MLI inhibition.

\section{Feedforward inhibition suppresses spontaneous PN activity}

At rest, $\mathrm{CF}$ inputs are spontaneously active at $\sim 1 \mathrm{~Hz}$. In vivo studies show that even with small increases or decreases in CF firing frequency (Colin et al., 1980; Montarolo et al., 1982; Demer et al., 1985; Savio and Tempia, 1985; Cerminara and Rawson, 2004), PN firing rates display a strong negative correlation with complex spikes. To mimic these manipulations in the CF activity pattern as the result of in vivo olivary stimulation, we used $2 \mathrm{~Hz}$ optical CF stimulation and measured PN spiking with in vitro extracellular recordings (Fig. 6A). We found a significant reduction in steady-state PN simple spike rate in response to $2 \mathrm{~Hz}$ stimulation ( $21 \pm 8 \%$ of control, $n=6$; Fig. $6 B, p<0.005)$. In addition, the timing of the first few simple spikes after the complex spike often had stereotypical intervals such that the phase of spontaneous simple spikes appeared to reset (Fig. 6B). Applica- tion of the $\mathrm{GABA}_{\mathrm{A}}$ receptor antagonist picrotoxin reduced the $\mathrm{CF}$ suppression of simple spikes to $52 \pm 5 \%$ of the prestimulus firing rate, a $31 \%$ reduction in the absolute suppression indicating that $\mathrm{CF}$ driven feedforward inhibition contributes to the profound effects of CFs on baseline PN spiking ( $p=0.002, n=6$; comparing "Picro $+2 \mathrm{~Hz}$ " stimulation to " $2 \mathrm{~Hz}$ " stimulation alone; Fig. $6 B-D)$. These data imply that the picrotoxin-sensitive component of the suppressed PN firing rate results from activation of MLIs, which further augments an intrinsic suppressive effect of $\mathrm{CFs}$ on firing rate.

To test whether the duration of postcomplex spike pauses are increased during synchronous CF activation, extracellular PN recordings were made to examine the duration of PN postcomplex spike pauses in the presence and absence of feedforward inhibition. In these experiments $\mathrm{CFs}$ were stimulated at a much lower frequency $(0.14 \mathrm{~Hz})$ to minimize tonic changes in MLI excitability. Postcomplex spike pauses were significantly reduced from $177 \pm 40$ to $110 \pm 22 \mathrm{~ms}$ upon blocking feedforward inhibition $(p=0.02, n=13$, Fig. $6 E, F)$. Pauses in control were on average $3.2 \pm 0.6$-fold longer in duration than the mean prestimulus spontaneous interval, and this relative pause duration was reduced to $2.4 \pm 0.4$-fold in the presence of picrotoxin $(p=$ $0.016, n=13)$. Moreover, there was no correlation $\left(R^{2}=0.064\right)$ between the magnitude of effects of picrotoxin on the pause du- 
A

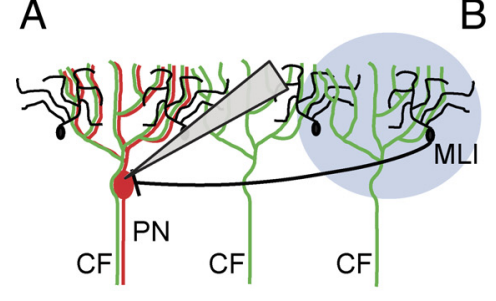

C

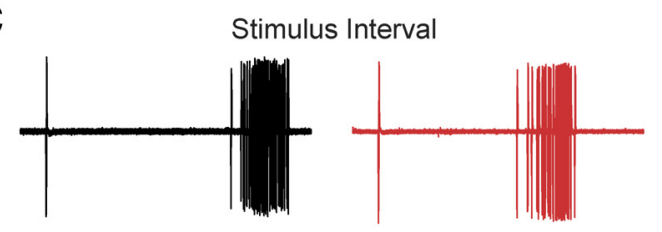

Subsequent Interval
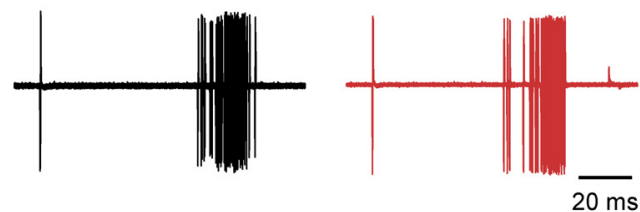

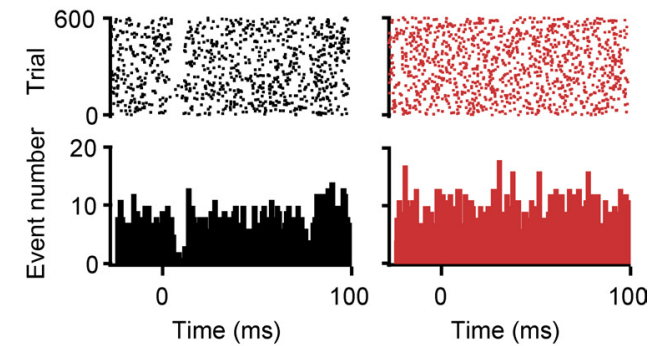

$\mathrm{D}$

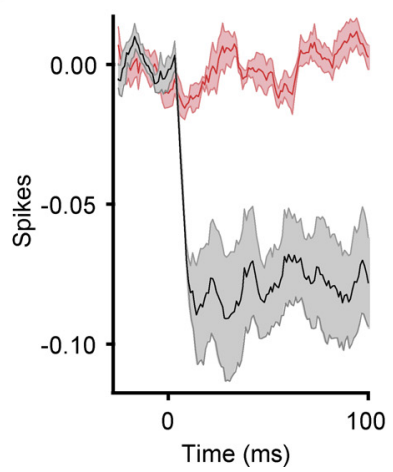

Figure 7. CF excitation of MLIs transiently inhibits spontaneous PN activity. A, Illustration of the optical stimulation paradigm used to activate CFs adjacent to an extracellularly recorded PN, allowing for CF-driven activation of adjacent MLIs. B, On the left in black is a control raster plot (top) and PSTH (bottom) from an example PN in response to 600 optical stimuli (1 ms light pulse, at $2 \mathrm{~Hz}$ ). On the right in red is a raster plot (top) and PSTH (bottom) from the same cell after bath application of picrotoxin. Bin, $2 \mathrm{~ms}$. C, The extracellular spikes occurring just before optical stimulation are temporally aligned (top) to illustrate the duration of intervals as the result of feedforward inhibition (first 60 trials from experiment shown in $\boldsymbol{B}$ ). Illustrated below is the duration of the subsequent interval obtained by aligning the peak amplitude of the spike occurring directly after the optical stimulation (i.e., the second spike shown above; $89.5 \pm 0.6 \mathrm{~ms} \mathrm{vs} 78.2 \pm 0.4 \mathrm{~ms}$ for the subsequent interval, $p<0.0001$ for this cell, $n=600$ trials). Unlike in control (black) the duration of the subsequent interval after application of picrotoxin (red) is not significantly shorter (65.7 \pm $0.1 \mathrm{~ms}$ v $65.40 .2 \mathrm{~ms}$ for subsequent interval, $p=0.22, n=600$ trials). $\boldsymbol{D}$, Summary cumPSTH illustrating the number of spikes lost as the result of feedforward inhibition before and after picrotoxin application ( $n=6$ neurons). Bin size, $1 \mathrm{~ms}$.

ration and on the prestimulus spontaneous interval, consistent with specific effects on CF-driven as opposed to general inhibition. These results confirm that phasic feedforward inhibition prolongs the postcomplex spike pause.

\section{CF-driven inhibition of PNs in the absence of direct excitatory $\mathrm{CF}$ input}

To test whether CFs can drive feedforward inhibition in PNs not receiving direct $\mathrm{CF}$ input, extracellular recordings from $\mathrm{PNs}$ were made, and the optical stimulus was adjusted so that neighboring CFs would be synchronously activated without activating the CF innervating the recorded PN (see Materials and Methods; Fig. $7 A$ ). Such optical stimuli generated brief, picrotoxin-sensitive pauses in PN activity that were time locked to the stimulus (Fig. $7 B$ ). Analysis of the intervals poststimulus showed that they were $10 \pm 2 \%$ longer compared with the immediate, subsequent interval (average decrease: $6 \pm 1 \mathrm{~ms}, n=6 ; p<0.005$ compared with no change; Fig. $7 B, C)$. Removing feedforward inhibition abolished these effects on interval duration $(1 \pm 0.5 \%$ interval difference; $n=6 ; p=0.01$ comparing control vs picrotoxin; $p>$ 0.05 compared with no change). It is likely that as a result of constraining the optical CF activation zone to the area just adjacent to the recorded PN only a small number of the possible MLIs that might inhibit the PN are activated. Indeed, the duration increases we observed are comparable to the $12 \%$ interval duration increases seen using paired MLI-to-PN recordings, indicating the effects we observed likely result from the effects of only a single MLI connected to the recorded PN (Häusser and Clark, 1997). This suggests that our findings likely underestimate the magnitude of the CF-driven feedforward inhibitory effect on PNs not receiving CF excitation. Together, these experiments further illustrate the effectiveness of the feedforward inhibition driven by CFs in the cerebellar cortex. Considering the extensive gap junction coupling between MLIs (Mann-Metzer and Yarom, 1999) and the divergent MLI-to-PN connectivity, the findings also further suggest that groups of PNs will be inhibited synchronously in response to specific types of spatiotemporal patterns of $\mathrm{CF}$ activity.

\section{Discussion}

\section{Synchronous CF activation drives feedforward inhibition of PNs}

The Marr, Albus, and Ito model of cerebellar learning proposes that CFs encode error signals that instruct changes in the strength of PF inputs to PNs (Marr, 1969; Albus, 1971; Ito, 1972). The salience of the CF signal in PNs in the form of a complex spike allows the CF pathway to transmit to PNs a highly distinctive, instructive signal. Although it has been suggested that CFs might deliver error signals to other sites in the cerebellar circuit, the technical challenge of stimulating CFs selectively has prevented progress on this issue. Here we took advantage of the specificity afforded by optogenetics to stimulate groups of CFs and showed that CFs also recruit a unique form of feedforward inhibition mediated by MLIs in the cerebellar cortex.

Feedforward inhibition contributes to the potent suppressive effects of CFs on PN spiking

In the absence of movement, a typical PN fires complex spikes at a rate of $\sim 1-2 \mathrm{~Hz}$ and fires conventional action potentials at $\sim 20-80 \mathrm{~Hz}$ (Granit and Phillips, 1956; Bell and Grimm, 1969; 
Bloedel and Roberts, 1971; Latham and Paul, 1971; Gilbert and Thach, 1977). Yet this low-frequency CF input exerts a profound short-term influence over the spiking output of PNs. In vivo, a robust feature of $\mathrm{PN}$ physiology is the inverse correlation between complex spike rate and simple spike rate (Colin et al., 1980; Montarolo et al., 1982; Demer et al., 1985; Savio and Tempia, 1985; Barmack and Yakhnitsa, 2003; Cerminara and Rawson, 2004), a phenomenon demonstrated in vitro by experiments detailed in this manuscript. CF suppression of simple spike firing is also commonly observed in response to sensory stimuli in that complex spike activity and PN firing are anticorrelated in time (Simpson and Alley, 1974; Stone and Lisberger, 1986; Raymond and Lisberger, 1998; Ke et al., 2009; Wulff et al., 2009; Barmack and Yakhnitsa, 2011), as well as within receptive field organization (Jörntell and Ekerot, 2002, 2003). Two mechanisms have been suggested to account for the suppressive influence of CFs on PN excitability. The first is that the complex spike engages small conductance $\mathrm{Ca}^{2+}$-activated potassium channels (often referred to as SK channels), thereby slowing PN spiking rate. This has been supported by slice experiments in which single CF inputs contribute to slowed firing and marked changes in patterned firing that are sensitive to SK channel antagonists (McKay et al., 2007). Our results clearly demonstrate a role for a second additional mechanism involving CF recruitment of synaptic inhibition, and explain in vivo observations such as pauses in the absence of complex spikes evoked by electrical stimuli delivered to the IO (Bloedel and Roberts, 1971; Latham and Paul, 1971; Murphy and Sabah, 1971), the absence of simple spike suppression by CFs when single CFs remain but neighboring CFs have been lesioned (Montarolo et al., 1982), and EPSPs in interneurons upon olive stimulation (Jörntell and Ekerot, 2002, 2003). Thus, the suppressive influence of CFs on baseline spiking we observe can be attributed to a combination of CF-driven synaptic inhibition and SK channel-mediated hyperpolarization.

\section{MLIs detect synchronous CF activity via glutamate spillover} The existence of a connection between CFs and MLIs has been a subject of debate for over 50 years. Light microscopy studies first suggested this possibility, demonstrating close apposition between CF endings and MLI dendrites (Scheibel and Scheibel, 1954). However, various groups using electron microscopy have failed to find ultrastructural evidence of contacts between CFs and MLIs (Desclin, 1976; Hámori and Szentágothai, 1980; Kollo et al., 2006). Yet, ample physiological evidence supports such a connection; CF-evoked synaptic inhibition has been proposed to explain postcomplex spike pauses (Granit and Phillips, 1956; Bell and Grimm, 1969; Bloedel and Roberts, 1971; Latham and Paul, 1971), and pauses in PN firing in the absence of a complex spike are observed in response to IO stimulation (Bloedel and Roberts, 1971; Latham and Paul, 1971; Murphy and Sabah, 1971). A small number of in vivo whole-cell MLI recordings provide still more direct evidence in the form of small EPSPs detectable in MLIs as a result of IO stimulation (Jörntell and Ekerot, 2003).

Our findings are in agreement with prior work showing that transfolial electrical stimuli can elicit spillover-mediated synaptic currents in MLIs with properties suggesting that they arise from CFs (Szapiro and Barbour, 2007). We confirm and extend these findings by demonstrating that such CF inputs recruit robust activity in a network of MLIs, which in turn synchronously inhibit groups of PNs. Despite resulting from spillover, we find that CF-to-MLI signaling generates large currents and occurs with millisecond precision at physiological temperatures. We speculate that this connection may operate in this manner because spillover-mediated communication is highly sensitive to the density of release sites, a property well suited to detect synchronous activity of CFs (Mukamel et al., 2009; Ozden et al., 2009; Ghosh et al., 2011).

\section{A possible role for CF-mediated, spillover-activated inhibition}

By relying on spillover, MLIs could serve as a filter, responding weakly to spontaneous discharge of individual CFs and more strongly to modular CF input, which has been suggested to encode errors or unexpected events (Najafi et al., 2011). The resulting inhibition of PNs would then be predicted to bind PNs together in response to CF-mediated error signals, generating synchronous pauses in groups of PNs. Although it is not known whether the PNs receiving synchronous CF input converge onto single neurons in the deep cerebellar nuclei, it has been recently shown that synchronization of PNs on a fast timescale can increase the excitability of deep cerebellar neurons (Person and Raman, 2012). Thus, the CF-to-MLI circuitry described here could read out error signals in the cerebellar cortex and convert them to transient bursts of disinhibition that could then influence neurons in the deep cerebellar nuclei, thereby instructing associative plasticity of MF inputs at this level of the circuit (Miles and Lisberger, 1981).

CF-to-MLI excitation could also be important for novel forms of circuit plasticity in the cerebellar cortex. In his landmark theoretical paper, Albus suggested a CF-driven form of potentiation at the PF-to-MLI synapse, a plasticity that would be complimentary to PF long-term depression in also decreasing PN activity (Albus, 1971). In fact, Albus envisioned a continuum of PF plasticity, equating PF-to-MLI potentiation to assigning negative synaptic weights to PFs. In vivo results strongly imply that CFs drive plasticity with these characteristics in MLIs (Jörntell and Ekerot, 2002), but the cellular details have not yet been examined. Future experiments will focus on whether the synaptic mechanism described here is involved.

In summary, our results identify a prominent role for a class of feedforward inhibitory neurons in CF signaling in the cerebellar cortex. The findings suggest that MLIs could serve to ensure that multiple forms of CF-driven associative plasticity, occurring at distributed sites within the cerebellar circuit, can result from the same CF-encoded error signal.

\section{References}

Albus JS (1971) A theory of cerebellar function. Mathematical Biosciences 10:25-61. CrossRef

Barmack NH, Shojaku H (1995) Vestibular and visual climbing fiber signals evoked in the uvula-nodulus of the rabbit cerebellum by natural stimulation. J Neurophysiol 74:2573-2589. Medline

Barmack NH, Yakhnitsa V (2003) Cerebellar climbing fibers modulate simple spikes in Purkinje cells. J Neurosci 23:7904-7916. Medline

Barmack NH, Yakhnitsa V (2011) Microlesions of the inferior olive reduce vestibular modulation of Purkinje cell complex and simple spikes in mouse cerebellum. J Neurosci 31:9824-9835. CrossRef Medline

Bell CC, Grimm RJ (1969) Discharge properties of Purkinje cells recorded on single and double microelectrodes. J Neurophysiol 32:1044-1055. Medline

Bloedel JR, Roberts WJ (1971) Action of climbing fibers in cerebellar cortex of the cat. J Neurophysiol 34:17-31. Medline

Cerminara NL, Rawson JA (2004) Evidence that climbing fibers control an intrinsic spike generator in cerebellar Purkinje cells. J Neurosci 24:4510 4517. CrossRef Medline

Colin F, Manil J, Desclin JC (1980) The olivocerebellar system. I. Delayed and slow inhibitory effects: an overlooked salient feature of cerebellar climbing fibers. Brain Res 187:3-27. CrossRef Medline

Demer JL, Echelman DA, Robinson DA (1985) Effects of electrical stimula- 
tion and reversible lesions of the olivocerebellar pathway on Purkinje cell activity in the flocculus of the cat. Brain Res 346:22-31. CrossRef Medline

Desclin JC (1976) Early terminal degeneration of cerebellar climbing fibers after destruction of the inferior olive in the rat. Synaptic relationships in the molecular layer. Anat Embryol 149:87-112. CrossRef Medline

Eccles J, Llinas R, Sasaki K (1964) Excitation of cerebellar Purkinje cells by the climbing fibres. Nature 203:245-246. CrossRef Medline

Fetz EE, Gustafsson B (1983) Relation between shapes of post-synaptic potentials and changes in firing probability of cat motoneurones. J Physiol 341:387-410. Medline

Ghosh KK, Burns LD, Cocker ED, Nimmerjahn A, Ziv Y, Gamal AE, Schnitzer MJ (2011) Miniaturized integration of a fluorescence microscope. Nat Methods 8:871-878. CrossRef Medline

Gilbert PF, Thach WT (1977) Purkinje cell activity during motor learning. Brain Res 128:309-328. CrossRef Medline

Granit R, Phillips CG (1956) Excitatory and inhibitory processes acting upon individual Purkinje cells of the cerebellum in cats. J Physiol 133: 520-547. Medline

Hámori J, Szentágothai J (1980) Lack of evidence of synaptic contacts by climbing fibre collaterals to basket and stellate cells in developing rat cerebellar cortex. Brain Res 186:454-457. CrossRef Medline

Häusser M, Clark BA (1997) Tonic synaptic inhibition modulates neuronal output pattern and spatiotemporal synaptic integration. Neuron 19:665-678. CrossRef Medline

Ito M (1972) Neural design of the cerebellar motor control system. Brain Res 40:81-84. CrossRef Medline

Jörntell H, Ekerot CF (2002) Reciprocal bidirectional plasticity of parallel fiber receptive fields in cerebellar Purkinje cells and their afferent interneurons. Neuron 34:797-806. CrossRef Medline

Jörntell H, Ekerot CF (2003) Receptive field plasticity profoundly alters the cutaneous parallel fiber synaptic input to cerebellar interneurons in vivo. J Neurosci 23:9620-9631. Medline

Ke MC, Guo CC, Raymond JL (2009) Elimination of climbing fiber instructive signals during motor learning. Nat Neurosci 12:1171-1179. CrossRef Medline

Kollo M, Holderith NB, Nusser Z (2006) Novel subcellular distribution pattern of A-type K+ channels on neuronal surface. J Neurosci 26: 2684-2691. CrossRef Medline

Latham A, Paul DH (1971) Spontaneous activity of cerebellar Purkinje cells and their responses to impulses in climbing fibres. J Physiol 213:135-156. Medline

Linden DJ, Connor JA (1995) Long-term synaptic depression. Annu Rev Neurosci 18:319-357. CrossRef Medline

Llinás R, Sugimori M (1980a) Electrophysiological properties of in vitro Purkinje cell somata in mammalian cerebellar slices. J Physiol 305: 171-195. Medline

Llinás R, Sugimori M (1980b) Electrophysiological properties of in vitro Purkinje cell dendrites in mammalian cerebellar slices. J Physiol 305: 197-213. Medline

Mann-Metzer P, Yarom Y (1999) Electrotonic coupling interacts with intrinsic properties to generate synchronized activity in cerebellar networks of inhibitory interneurons. J Neurosci 19:3298-3306. Medline

Marr D (1969) A theory of cerebellar cortex. J Physiol 202:437-470. Medline

Mattis J, Tye KM, Ferenczi EA, Ramakrishnan C, O'Shea DJ, Prakash R, Gunaydin LA, Hyun M, Fenno LE, Gradinaru V, Yizhar O, Deisseroth K (2012) Principles for applying optogenetic tools derived from direct comparative analysis of microbial opsins. Nat Methods 9:159-172. Medline

Mauk MD, Steinmetz JE, Thompson RF (1986) Classical conditioning using stimulation of the inferior olive as the unconditioned stimulus. Proc Natl Acad Sci U S A 83:5349-5353. CrossRef Medline

McKay BE, Engbers JD, Mehaffey WH, Gordon GR, Molineux ML, Bains JS, Turner RW (2007) Climbing fiber discharge regulates cerebellar functions by controlling the intrinsic characteristics of Purkinje cell output. J Neurophysiol 97:2590-2604. CrossRef Medline

Medina JF, Lisberger SG (2008) Links from complex spikes to local plasticity and motor learning in the cerebellum of awake-behaving monkeys. Nat Neurosci 11:1185-1192. CrossRef Medline

Medina JF, Nores WL, Mauk MD (2002) Inhibition of climbing fibres is a signal for the extinction of conditioned eyelid responses. Nature 416:330 333. CrossRef Medline

Miles FA, Lisberger SG (1981) Plasticity in the vestibulo-ocular reflex: a new hypothesis. Annu Rev Neurosci 4:273-299. CrossRef Medline

Montarolo PG, Palestini M, Strata P (1982) The inhibitory effect of the olivocerebellar input on the cerebellar Purkinje cells in the rat. J Physiol 332:187-202. Medline

Mukamel EA, Nimmerjahn A, Schnitzer MJ (2009) Automated analysis of cellular signals from large-scale calcium imaging data. Neuron 63: 747-760. CrossRef Medline

Murphy JT, Sabah NH (1971) Cerebellar Purkinje cell responses to afferent inputs. I. Climbing fiber activation. Brain Res 25:449-467. CrossRef Medline

Najafi F, Giovannucci A, Kloth AD, Wang SSH-, Medina JF (2011) Climbing fibers code for the strength of periorbital airpuff stimuli in single trials. Soc Neurosci Abstr 37:183.18.

Ochiishi T, Yamauchi T, Terashima T (1998) Regional differences between the immunohistochemical distribution of $\mathrm{Ca} 2+/$ calmodulin-dependent protein kinase II alpha and beta isoforms in the brainstem of the rat. Brain Res 790:129-140. CrossRef Medline

Ozden I, Sullivan MR, Lee HM, Wang SS (2009) Reliable coding emerges from coactivation of climbing fibers in microbands of cerebellar Purkinje neurons. J Neurosci 29:10463-10473. CrossRef Medline

Palkovits M, Magyar P, Szentágothai J (1972) Quantitative histological analysis of the cerebellar cortex in the cat. IV. Mossy fiber-Purkinje cell numerical transfer. Brain Res 45:15-29. CrossRef Medline

Person AL, Raman IM (2012) Purkinje neuron synchrony elicits timelocked spiking in the cerebellar nuclei. Nature 481:502-505. Medline

Raymond JL, Lisberger SG (1998) Neural learning rules for the vestibuloocular reflex. J Neurosci 18:9112-9129. Medline

Savio T, Tempia F (1985) On the Purkinje cell activity increase induced by suppression of inferior olive activity. Exp Brain Res 57:456-463. Medline

Scheibel ME, Scheibel AB (1954) Observations on the intracortical relations of the climbing fibers of the cerebellum; a Golgi study. J Comp Neurol 101:733-763. CrossRef Medline

Simpson JI, Alley KE (1974) Visual climbing fiber input to rabbit vestibulocerebellum: a source of direction-specific information. Brain Res 82:302308. CrossRef Medline

Stone LS, Lisberger SG (1986) Detection of tracking errors by visual climbing fiber inputs to monkey cerebellar flocculus during pursuit eye movements. Neurosci Lett 72:163-168. CrossRef Medline

Szapiro G, Barbour B (2007) Multiple climbing fibers signal to molecular layer interneurons exclusively via glutamate spillover. Nat Neurosci 10 : 735-742. CrossRef Medline

Welsh JP, Harvey JA (1998) Acute inactivation of the inferior olive blocks associative learning. Eur J Neurosci 10:3321-3332. CrossRef Medline

Wulff P, Schonewille M, Renzi M, Viltono L, Sassoè-Pognetto M, Badura A, Gao Z, Hoebeek FE, van Dorp S, Wisden W, Farrant M, De Zeeuw CI (2009) Synaptic inhibition of Purkinje cells mediates consolidation of vestibulo-cerebellar motor learning. Nat Neurosci 12:1042-1049. CrossRef Medline 